\title{
EMT transcription factors snail and slug directly contribute to cisplatin resistance in ovarian cancer
}

\author{
Alexandria M Haslehurst ${ }^{1}$, Madhuri Koti ${ }^{1}$, Moyez Dharsee ${ }^{4}$, Paulo Nuin ${ }^{1,4}$, Ken Evans $^{1,4}$, Joseph Geraci ${ }^{4}$, \\ Timothy Childs ${ }^{1}$, Jian Chen ${ }^{4}$, Jieran $\mathrm{Li}^{4}$, Johanne Weberpals ${ }^{2}$, Scott Davey ${ }^{1}$, Jeremy Squire ${ }^{1,3}$, Paul C Park ${ }^{1}$ and \\ Harriet Feilotter ${ }^{1,4^{*}}$
}

\begin{abstract}
Background: The epithelial to mesenchymal transition (EMT) is a molecular process through which an epithelial cell undergoes transdifferentiation into a mesenchymal phenotype. The role of EMT in embryogenesis is wellcharacterized and increasing evidence suggests that elements of the transition may be important in other processes, including metastasis and drug resistance in various different cancers.

Methods: Agilent $4 \times 44 \mathrm{~K}$ whole human genome arrays and selected reaction monitoring mass spectrometry were used to investigate mRNA and protein expression in A2780 cisplatin sensitive and resistant cell lines. Invasion and migration were assessed using Boyden chamber assays. Gene knockdown of snail and slug was done using targeted siRNA. Clinical relevance of the EMT pathway was assessed in a cohort of primary ovarian tumours using data from Affymetrix GeneChip Human Genome U133 plus 2.0 arrays.

Results: Morphological and phenotypic hallmarks of EMT were identified in the chemoresistant cells. Subsequent gene expression profiling revealed upregulation of EMT-related transcription factors including snail, slug, twist2 and zeb2. Proteomic analysis demonstrated up regulation of Snail and Slug as well as the mesenchymal marker Vimentin, and down regulation of E-cadherin, an epithelial marker. By reducing expression of snail and slug, the mesenchymal phenotype was largely reversed and cells were resensitized to cisplatin. Finally, gene expression data from primary tumours mirrored the finding that an EMT-like pathway is activated in resistant tumours relative to sensitive tumours, suggesting that the involvement of this transition may not be limited to in vitro drug effects.

Conclusions: This work strongly suggests that genes associated with EMT may play a significant role in cisplatin resistance in ovarian cancer, therefore potentially leading to the development of predictive biomarkers of drug response or novel therapeutic strategies for overcoming drug resistance.
\end{abstract}

\section{Background}

Of the gynecological malignancies, ovarian cancer has the highest associated mortality rate in the western world [1,2]. While relatively rare at 1 in 71 women affected in Canada [3], approximately $70-80 \%$ of patients with ovarian cancer will succumb to the disease within five years of diagnosis [4]. The high mortality rate is due, in part, to the fact that ovarian cancer is often

\footnotetext{
* Correspondence: feilotth@kgh.kari.net

'Department of Pathology and Molecular Medicine, Queen's University, 88

Stuart Street, Kingston, ON, K7L3N6, Canada

Full list of author information is available at the end of the article
}

diagnosed in advanced stage, because of a lack of measurable early symptoms and ineffective screening techniques $[5,6]$. Of equal importance, $20 \%$ of tumours display primary resistance to platinum compounds while the majority of initial responders will relapse, often as a result of acquired drug resistance $[7,8]$.

Standard treatment for ovarian cancer involves tumour debulking and platinum-based chemotherapy administered intravenously or intraperitoneally $[9,10]$. Cisplatin, the most common first line chemotherapeutic drug, is a platinum compound that binds to and crosslinks DNA [11]. During cell division cisplatin-DNA

\section{Biomed Central}


adducts block replicative machinery, inducing the DNA damage response, and eventually apoptosis $[11,12]$. It has been proposed that decreased cellular uptake of drug as well as increased capacity for DNA damage repair and anti-apoptotic signaling may play a role in cisplatin resistance displayed by many tumours [12-17].

Recent evidence has suggested that processes of the epithelial to mesenchymal transition (EMT) may play a role in the development of chemoresistance. EMT is a critical process in embryogenesis [18] and has been well studied in that context. It is characterized by up-regulation of extracellular matrix components, a loss of intercellular cohesion, increased rate of cellular migration and invasion, as well as increased resistance to apoptosis, and is modulated by a number of transcription factors, namely SNAI1 (Snail) and SNAI2 (Slug) $[19,20]$. In early embryogenesis, these cellular traits enable both the formation of the germinal layers during gastrulation by facilitating formation of the mesoderm and endoderm from cells in the primitive streak, and derivation of migratory neural crest cells from the epithelial neural plate [21]. EMT also has a significant role later in embryo development during tissue reorganization and organ modeling $[22,23]$. The same cellular remodeling and signaling networks appear to be active during metastasis, and may also contribute to the development of drug resistance in tumour cells [24-26]. During cancer progression, EMT appears to promote dissemination of cells from the tumour mass [27] and facilitates tissue invasion by regulating the production of matrix metalloproteases and altering cytoskeletal organization [28,29]. In models of drug resistant breast and ovarian cancers, EMT gene signatures have been found to correlate with the presence of drug resistance [30,31] and manipulation of EMT transcriptional regulators modulates resistance to chemotherapeutic drugs in lung and bladder cancers $[32,33]$. Additional evidence suggests that EMT may contribute to the acquisition of drug resistance by altering expression of key genes involved in cell cycle regulation, drug transport and apoptosis [34-36].

We hypothesized that the genes that regulate EMT have a role in cisplatin resistance in ovarian cancer. Using a cell line model of cisplatin-resistant ovarian cancer, we demonstrate features of a mesenchymal phenotype in the resistant cells relative to their epithelial parent cells. Additionally, we demonstrate increased capacity for migration and invasion in resistant compared to sensitive cells, characteristics that are reverted following reduction of expression of snail and slug. Using a cohort of primary human ovarian tumours, we demonstrate that EMT genes are upregulated in chemonaïve drug resistant tumours, suggesting that these genes may act as biomarkers of chemotherapy resistance. Finally, we modulate resistance to cisplatin in
A2780cis cells by manipulating levels of snail and slug, suggesting that the key regulators of EMT are directly contributing to the drug resistant phenotype in ovarian cancer cells.

\section{Methods}

\section{Cell lines and culture conditions}

The cisplatin-sensitive A2780 ovarian adenocarcinoma cell line and its daughter line, A2780cis, were obtained from the European Collection of Cell Cultures (Salisbury, UK). Cells were cultured in RPMI with $10 \% \mathrm{FBS}$, $1 \%$ penicillin/streptomycin and $1 \% \mathrm{~L}$-glutamine at $37^{\circ} \mathrm{C}$ in $5 \% \mathrm{CO}_{2}$. A2780cis cells were maintained in media with $1 \mu \mathrm{M}$ cisplatin. For all assays, cells were grown to 70-80\% confluence and harvested following trypsinization. Analysis of cell morphology was done at $20 \times$ magnification using a Zeiss Axiovert 25 Phase Contrast Inverted Microscope. Digital images were captured using a Canon Power Shot G10 equipped with a Carl Zeiss 426126 lens.

\section{Human ovarian tumours}

Consent for tumour banking was obtained and the study was approved by the Research Ethics Boards at both Kingston General Hospital and The Ottawa Hospital. Tumour samples were obtained from the Division of Gynecologic Oncology Ovarian Tissue Bank and the Ontario Tumour Bank. All tumours were chemonaïve at collection. Seventeen tumours were classified as chemosensitive (progression-free interval of greater than 18 months) and eleven as chemoresistant (progression-free interval of less than 8 months) using available follow-up clinical data. Histological assessment of samples confirmed that each sample contained $>70 \%$ tumour cells.

\section{Gene expression profiling and analysis}

Total RNA was extracted from the cell lines and tumours using the Qiagen miRNeasy Mini kit (Toronto, Canada). RNA quality was assessed to have an RNA integrity number of at least eight using an Agilent 2100 Bioanalyzer (Mississauga, Canada). For cell lines, total RNA was labeled with Cyanine-3 dye using a Quick Amp Labeling Kit (Agilent, Mississauga, Canada) and hybridized to Agilent Whole Human Genome $(4 \times 44 \mathrm{~K})$ Microarrays (Mississauga, Canada) for 17 hours in a rotating SciGene model 700 oven (Sunnyvale, USA). Arrays were scanned using an Agilent Technologies DNA Microarray Scanner and data were feature extracted using Feature Extraction Software 10.5.1.1 (Agilent) and statistically analyzed using default settings on GeneSpring GX 11.0.1 software (Agilent).

Expression profiles from the tumor RNA were obtained using Affymetrix GeneChip Human Genome 
U133 plus 2.0 arrays. Raw data were imported into GeneSpring GX 11.0.1 and analyzed. Unsupervised hierarchical clustering of the tumour samples was completed using the self-organizing maps algorithm in the GeneSpring GX 11.0.1 package.

\section{qRT-PCR Taqman ${ }^{\text {TM }}$ arrays}

Snail and Slug expression levels were analyzed using Taqman ${ }^{\mathrm{TM}}$ assays (Applied Biosystems, Streetsville, Canada, item Hs00195591_m1 and item Hs00950344_m1) and the SuperScript III First-Strand Synthesis SuperMix kit for qRT-PCR (Invitrogen, Burlington, Canada). PCR conditions were $50^{\circ} \mathrm{C}$ for 2 minutes, $95^{\circ} \mathrm{C}$ for 10 minutes, 40 cycles of $95^{\circ} \mathrm{C}$ for 15 seconds, $60^{\circ} \mathrm{C}$ for 1 minute. GAPDH was used as an internal control. As a measure of relative change in expression between the parental and resistant samples, $\Delta \Delta \mathrm{Ct}$ values were calculated and converted to approximate fold change values $\left(2^{-\Delta \Delta \mathrm{Ct}}\right)$ [37].

\section{Cell proliferation assay}

Cells were plated in 24-well plates at $5 \times 10^{4}$ cells/well. Cells were harvested and counted using a haemocytometer after 24, 48 and 72 hours. Average cell counts were used to produce growth curves, from which cell doubling time was calculated.

\section{Wound healing assay}

Cell migration was assessed using wound-healing assays. Cells were grown in a confluent monolayer in a $60 \mathrm{~mm}$ plate. A wound was inflicted in the cell layer by scratching the plate with a sterile pipette tip. Plates were rinsed gently with media twice prior to incubation to remove non-adherent cells. Digital images of the wound were obtained at times 0 hours, 12 hours and 36 hours at $10 \times$ magnification. Effects of proliferation were controlled for by using a reduced serum medium (3\%FBS) and monitored via cell count.

\section{Boyden chamber migration and invasion assays}

Cells were serum starved for 24 hours prior to use. Media with $10 \%$ FBS was added to the wells of a 24well plate. BD Falcon ${ }^{\mathrm{TM}}$ Cell Culture Inserts (BD Biosciences, Mississauga, Canada) were placed in each well. $2 \times 10^{3}$ cells in serum-free media were added to the interior of each insert. Plates were incubated for 24 hours at $37^{\circ} \mathrm{C}$ in $5 \% \mathrm{CO}_{2}$, and media removed from the insert, which was then washed with PBS. Insert membranes were fixed with cold methanol for 10 minutes, stained with $0.5 \%$ Crystal Violet in $25 \%$ methanol for 10 mins and rinsed with water to remove excess dye. Membranes were removed from the insert, placed under a microscope and the number of cells that migrated through the porous membrane was counted.
Invasion assays were done as described above using BD BioCoat ${ }^{\mathrm{TM}}$ Matrigel $^{\mathrm{TM}}$ invasion chambers (BD Biosciences, Mississauga, Canada).

\section{MTT assays}

$5 \times 10^{3}$ cells/well were seeded in 96-well plates in 100 ul medium with $10 \mu \mathrm{M}$ cisplatin and without phenol red and left to incubate for 48 hours at $37^{\circ} \mathrm{C}$ and $5 \%$ $\mathrm{CO}_{2}$. After 48 hours, $10 \mu \mathrm{l}$ MTT (3-(4,5-Dimethylthiazol-2-yl)-2,5-diphenyltetrazolium bromide) (SigmaAldrich, Oakville, Canada) was added to each well and cells were left for 4 hours. After incubation, $150 \mu \mathrm{l}$ MTT solvent $(0.1 \mathrm{~N} \mathrm{HCl}$ in anhydrous isopropanol) was added to each well and mixed thoroughly by pipetting until all formazan crystals were dissolved. Colourimetric change was measured at $570 \mathrm{~nm}$ and background absorbance at $690 \mathrm{~nm}$. Final values were obtained by subtracting OD690 $\mathrm{nm}$ from OD570 $\mathrm{nm}$. MTT assays for siRNA optimization were done without adding cisplatin and the initial seeded cells were only incubated for 24 hours prior to MTT addition.

\section{Gene knockdown}

Pre-designed siRNA oligos for snail (cat\# SASI_Hs01_00039785, duplex sequences: 5'GCCUUCAACUGCAAAUACU and 5'AGUAUUUGCAGUUGAAGGC) and slug (cat\# SASI_Hs01_00159363, duplex sequences: 5'GCAUUUGCAGACAGGUCAA and 5'UUGACCUGUCUGCAAAUGC) were purchased from Sigma-Aldrich (Oakville, Canada).

Optimization of gene knockdown was done using AllStars Hs Cell Death Control siRNA (Qiagen, Toronto, Canada), a mix of siRNAs that target genes essential for cell survival. $5 \times 10^{4}$ cells/well were plated in 24-well plates and incubated overnight. After 24 hours cells were transfected with $7.5 \mathrm{ng}, 19 \mathrm{ng}, 37.5 \mathrm{ng}$ or $75 \mathrm{ng}$ of AllStars Hs Cell Death Control siRNA and $1.5 \mu \mathrm{l}, 3 \mu \mathrm{l}$ or $7.5 \mu \mathrm{l}$ of HiPerFect Transfection Reagent (Qiagen, Toronto, Canada). Cells were incubated for 72 hours and cell death measured using MTT assays. Maximum cell death was achieved using $19 \mathrm{ng}$ siRNA with $3 \mu \mathrm{l}$ of transfection reagent. Optimal time points were then established using siRNA targeted against Snail and Slug. 24, 48 and 72 hours after transfection the level of snail and slug transcript was determined by qRT-PCR TaqMan assay. Optimal knockdown of both genes was seen 72 hours post transfection. Efficiency of transfection in the A2780 and A2780cis cells was determined to be $87 \%$ and $84 \%$, respectively.

For knockdown experiments, $5 \times 10^{4}$ cells/well were plated in 24-well plates and incubated overnight. $19 \mathrm{ng}$ of siRNA and $3 \mu \mathrm{l}$ of HiPerFect transfection reagent were diluted in $100 \mu \mathrm{l}$ serum-free RPMI and were incubated for 10 minutes at room temperature. Transfection 
complexes were then added drop-wise onto the cells. Cells were incubated for 72 hours at $37^{\circ} \mathrm{C}$ and $5 \% \mathrm{CO} 2$. Media was changed as necessary. Transfection of A2780cis cells with AllStars Negative Control (Qiagen), an siRNA sequence with no homology to any known mammalian gene, was used as a control for this experiment. Cells with reduced expression were designated as follows: A2780cisSN - snail knockdown, A2780cisSL slug knockdown, A2780cisSN/SL - both snail and slug knocked down.

\section{Statistical analysis}

Each assay was performed in triplicate. Data are expressed as the mean \pm standard deviation (SD). Statistical significance of all data was evaluated using the Student's $t$-test, $\mathrm{p}<0.05$.

\section{Sample preparation for proteomic analysis}

Samples were lysed in RIPA buffer containing Halt Protease and Phosphatase Inhibitor Cocktail (PIERCE, IL, USA). Cells were sonicated and lysates incubated at $4^{\circ} \mathrm{C}$ for 30 minutes with shaking. Supernatants were separated by centrifugation for 15 minutes at $4^{\circ} \mathrm{C}$. Protein concentration was measured with a Bio-Rad DC Protein Assay kit and $30 \mu \mathrm{g}$ of protein was used for tryptic digestion. Each aliquot was dried, dissolved in $0.5 \mathrm{M}$ triethylammonium bicarbonate (TEAB), reduced by adding $2 \mu \mathrm{l}$ of tris-(2-carboxyethyl)-phosphine (TCEP), incubated at room temperature for 1 hour, alykalted using $1 \mu \mathrm{l}$ of methyl methane thiosulfonate (MMTS) and incubated at room temperature for 1 hour in the dark. $2 \mu \mathrm{g}$ trypsin was added for overnight digestion at $37^{\circ} \mathrm{C}$. The tryptic digest was desalted by using a $\mathrm{C} 18$ spin column (PIERCE, USA), dried under vaccum and resuspended in $0.1 \%$ formic acid for SRM analysis.

\section{LC/SRM-MS analysis}

The LC/SRM-MS analytical system consisted of an Eksigent nanoflow HPLC (AB Sciex, USA) coupled to a 5500 QTRAP $^{\circledR}$ hybrid triple quadrupole/linear ion trap mass spectrometer (AB SCIEX, USA). $1 \mu \mathrm{g}$ of digested protein was loaded onto a trap column $(0.3 \mathrm{~mm}$ I.D, 5 mm L), packed with $5 \mu \mathrm{m}$ Zorbax SB-C18, $300 \AA$ pore (Agilent, USA). Peptides were separated on a $75 \mu \mathrm{m}$ I. D., $15 \mathrm{~cm}$ long nanoflow column with $15 \mu \mathrm{m}$ spray tip (New Objectives, USA). A linear gradient profile was employed starting from $5 \%$ solvent B to $40 \%$ B in 60 minutes (solvent A was $2 \%$ acetonitrile in water with $0.1 \%$ formic acid; solvent B was $2 \%$ water in acetonitrile with $0.1 \%$ formic acid). The ion spray voltage was set at $2300 \mathrm{~V}$, and source temperature at $160^{\circ} \mathrm{C}$. The declustering voltage was $100 \mathrm{~V}$, and collision energy value was selected for each transition as generated by MultiQuant ${ }^{\circledR}$ software (AB Sciex, USA). To ensure sensitive and reliable quantification, tryptic peptides and SRM transitions were generated by MRMPilot software (AB SCIEX, USA) based on common chemical rules of peptide fragmentation. The specificity of each peptide was verified using BLAST alignment against the NCBI-NR human protein database. Raw SRM-MS data was preprocessed using MultiQuant 2.0.2 software (AB SCIEX). A 2-point Gaussian smoothing window was applied to all transition peaks. Peak area for each transition was averaged over three replicate experiments per resistant and sensitive cell line sample; fold-change was calculated from the ratio of the average peak area in resistant cells to that in sensitive cells. A transition was discarded if peak area coefficient of variation (CV) across replicates was greater than 0.2 or peak area in any replicate was below the 25th percentile. Peptides with at least 2 transitions satisfying these constraints were conserved.

\section{Results}

Cisplatin resistance in A2780cis correlates with changes in cellular morphology consistent with EMT signaling

We examined the morphological characteristics of the cell lines during exponential growth. Parental A2780 cells formed cohesive clusters with round cellular morphology in vitro (Figure 1a), consistent with an epithelial phenotype. In contrast, A2780cis cells, grown in the presence of $1 \mu \mathrm{M}$ cisplatin, display a spindle-like morphology and formed dyscohesive sheets (Figure 1b). Additionally, the resistant cells exhibit the formation of pseudopodia (Figure 1b, inset), not seen in the parental cells.

\section{Whole transcriptome profiling and LC/SRM-MS analysis identify components of EMT signaling networks in A2780cis relative to $\mathrm{A} 2780$}

To confirm the involvement of EMT elements in the development of cisplatin resistance, whole transcriptome microarrays (Agilent, Mississauga, Canada) were used to

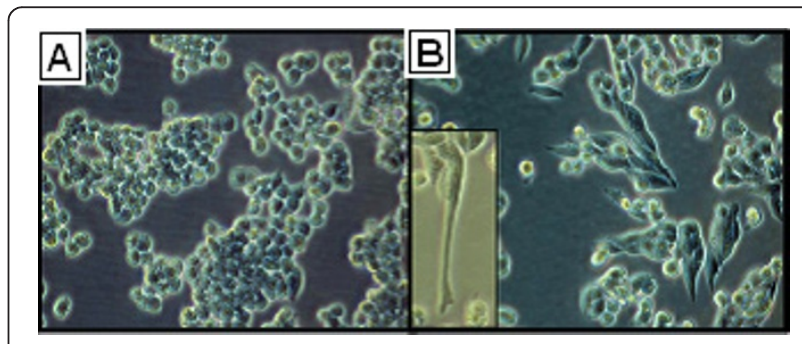

Figure 1 Morphology of A2780 and A2780cis cells. Cells visualized under $20 \times$ magnification. Drug sensitive cells (a) have round morphology and grow in tight clusters with substantial cellular cohesion. Comparatively, the drug resistant cells (b) have a more fibroblastic appearance and demonstrate reduced intercellular contacts. Additionally, drug resistant cells extend pseudopodia (inset). 
compare gene expression between A2780 and A2780cis cells during exponential growth. In repeated assays, EMT pathway elements, including snail, slug, twist2 and $z e b 2$, were over-expressed in the cisplatin-resistant cell line relative to the parental line (Figure 2a). Technical validation by qRT-PCR using Taqman assays confirmed relative overexpression of snail by $3.7 \pm 0.3$ (SD) fold and slug by $6.9 \pm 0.4$ (SD) fold, in the drug-resistant cells compared to the drug-sensitive cells (Figure 2b). Protein analysis by liquid chromatography/selected reaction monitoring mass spectrometry (LC/SRM-MS) confirmed upregulation of Snail, Slug and vimentin, as well as downregulation of epithelial marker E-cadherin in the drug resistant cells relative to the drug sensitive cells (Table 1).

\section{Cisplatin resistant cells display increased potential for migration and invasion}

Migratory capacity was measured using Boyden chamber assays. In three independent experiments, $23.7 \pm 5.1$

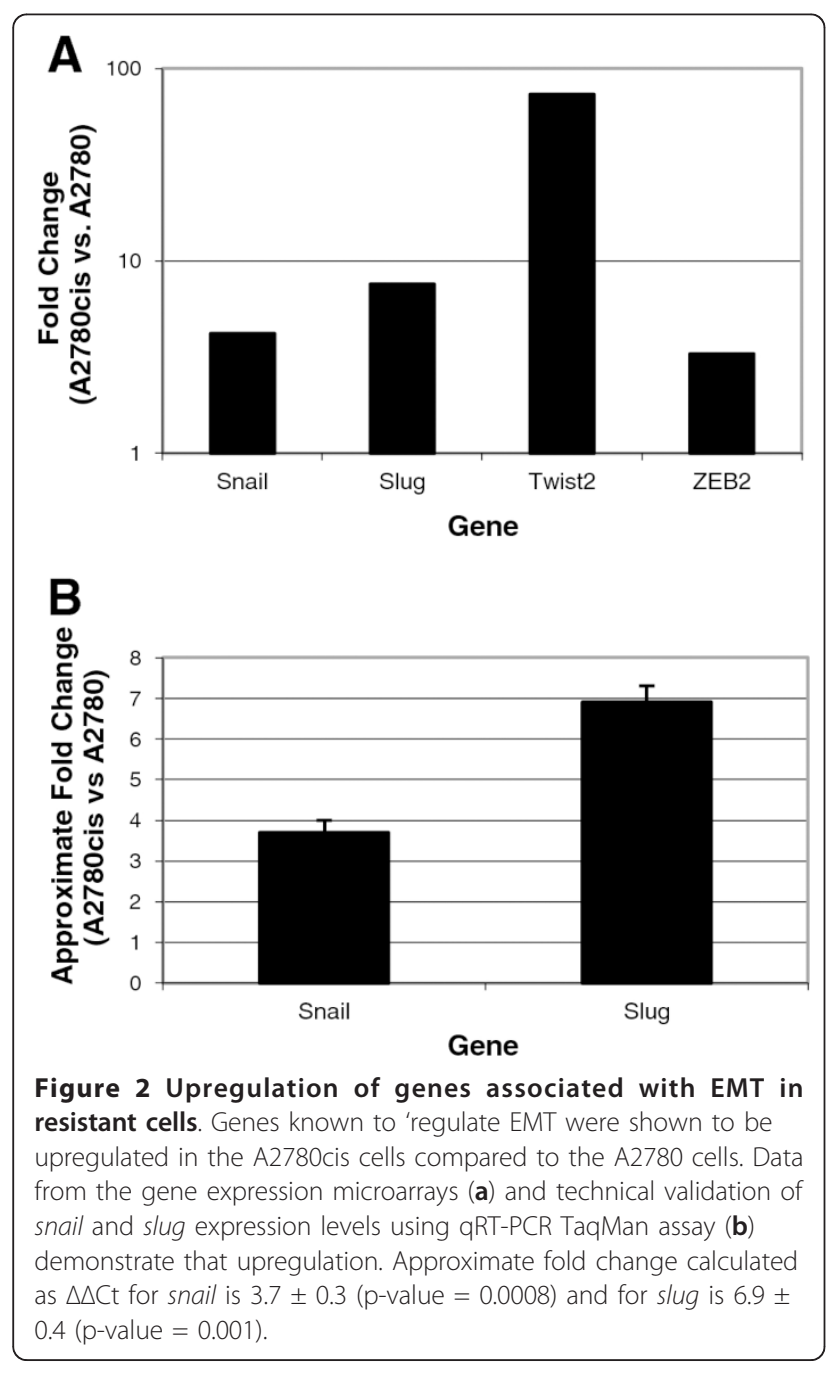

drug sensitive cells and $194.0 \pm 7.0$ drug-resistant cells migrated through the membrane after 24 hours ( $\mathrm{p}$-value $=0.003$ ) (Figure 3c). Resistant cells also showed a fivefold increased invasive capability relative to sensitive cells using a Matrigel-coated Boyden chamber assay. After 24 hours, an average of $36.3 \pm 5.03$ sensitive cells and $188.3 \pm 4.04$ resistant cells invaded the matrix (pvalue $=0.003)$ (Figure $3 \mathrm{c}$ ).

\section{Knockdown of snail and slug reverses the EMT phenotype} and reduces cellular resistance to cisplatin

SiRNA was used to reduce the levels of snail and slug transcript in the A2780cis cells to those of the parent A2780 cell line (A2780cisSN - snail knockdown, A2780cisSL - slug knockdown, A2780cisSN/SL - both snail and slug knocked down). Knockdown of these genes was confirmed by qRT-PCR (results not shown) and resulted in reversion of cell morphology of the resistant cells to that of the parent cell line (Figure 3a). Additionally, the knockdowns resulted in a reduction of the doubling time of the resistant cells from $45.7 \pm 2.4$ hours to $31.1 \pm 2.4$ hours ( $\mathrm{p}$-value $=0.017$ ), similar to the $27.3 \pm 1.6$ hour doubling time of the drug-sensitive A2780 cells $(\mathrm{p}$-value $=0.15)$ (Figure $3 \mathrm{~b})$. Migratory capacity of the transfected cells was reduced from 194.0 \pm 7.0 (untransfected controls) to $33.67 \pm 3.1$ cells migrating through the membrane $(\mathrm{p}$-value $=0.002)$ (Figure 3c). Invasive capability was reduced from $188.3 \pm$ 4.04 (untransfected controls) to $56 \pm 4.58$ cells invading the matrix (p-value $=0.004)$ (Figure 3c). Finally, we showed increased cellular sensitivity to cisplatin in transfected cells relative to controls (Figure 4). Following 48 hours of growth in $10 \mu \mathrm{M}$ cisplatin, transfected cells displayed $62 \pm 2.5 \%$ cell death compared to controls at $37 \pm 2.4 \%(\mathrm{p}$-value $=0.005)$. As a comparator, parental drug-sensitive cells displayed $75 \pm 3.3 \%$ cell death.

\section{Drug resistant human ovarian tumours can be} differentiated from drug sensitive ovarian tumours using a biomarker panel of EMT-related genes

Human ovarian tumour samples were classified as chemosensitive (progression-free interval of greater than 18 months) or chemoresistant (progression-free interval of less than 6 months) based on available clinical data (Additional file 1: Table S1). Gene expression data from 17 sensitive and 11 resistant tumours were mined to investigate the relative expression levels of EMT-related genes. In addition to snail, slug, twist2 and zeb2, the resistant tumour samples also showed increased expression of twist1 and zeb1, two other important regulators of EMT (Figure 5a). We used published information about EMT to derive a list of 17 additional genes with a role directly upstream or downstream of Snail and Slug (Table 2). Unsupervised hierarchical clustering using 
Table 1 Targeted protein analysis of A2780 and A2780cis cells.

\begin{tabular}{|c|c|c|c|c|c|c|c|}
\hline \multirow[t]{2}{*}{ Protein } & \multirow[t]{2}{*}{ Peptide } & \multirow[t]{2}{*}{ Fragment Change } & \multirow[t]{2}{*}{ Fold } & \multicolumn{2}{|c|}{ Mean Peak Area } & \multicolumn{2}{|c|}{ CV } \\
\hline & & & & Sensitive & Resistant & Sensitive & Resistant \\
\hline \multirow[t]{8}{*}{ E- cadherin } & & b8 & -1.18 & $5.82 \mathrm{E}+04$ & $3.22 \mathrm{E}+04$ & 0.01 & 0.13 \\
\hline & GPFPKNLVQJK & b9 & -1.55 & $1.57 \mathrm{E}+04$ & $1.01 \mathrm{E}+06$ & 0.07 & 0.08 \\
\hline & & b10 & -1.63 & $3.33 \mathrm{E}+04$ & $2.05 E+04$ & 0.03 & 0.19 \\
\hline & & y8 & -4.48 & $2.10 \mathrm{E}+04$ & $5.02 \mathrm{E}+03$ & 0.09 & 0.10 \\
\hline & VFYSITGQADTPPVGVFIIER & y9 & -4.16 & $8.25 E+04$ & $1.99 \mathrm{E}+04$ & 0.02 & 0.12 \\
\hline & & $\mathrm{y} 10$ & -4.01 & $8.45 E+04$ & $2.11 \mathrm{E}+04$ & 0.07 & 0.11 \\
\hline & & y6 & 1.15 & $4.78 \mathrm{E}+06$ & $2.52 \mathrm{E}+06$ & 0.01 & 0.01 \\
\hline & EYQDLLNVK & $y 7$ & 1.14 & $2.19 \mathrm{E}+06$ & $2.50 \mathrm{E}+06$ & 0.02 & 0.01 \\
\hline \multirow[t]{6}{*}{ Vimentin } & & y8 & 1.11 & $1.27 \mathrm{E}+05$ & $1.14 \mathrm{E}+05$ & 0.02 & 0.05 \\
\hline & & y6 & 1.01 & $4.58 \mathrm{E}+06$ & $4.62 E+06$ & 0.02 & 0.03 \\
\hline & ILLAELEQLK & $y 7$ & 1.08 & $7.34 \mathrm{E}+06$ & $7.94 \mathrm{E}+06$ & 0.04 & 0.05 \\
\hline & & y8 & 1.10 & $1.11 \mathrm{E}+07$ & $1.22 \mathrm{E}+07$ & 0.04 & 0.04 \\
\hline & & y9 & 1.08 & $1.35 \mathrm{E}+06$ & $1.47 \mathrm{E}+06$ & 0.04 & 0.04 \\
\hline & & b3 & 1.25 & $6.00 E+04$ & $7.50 \mathrm{E}+04$ & 0.14 & 0.03 \\
\hline \multirow[t]{3}{*}{ Snail } & SFLVR & b4 & 1.21 & $7.38 \mathrm{E}+04$ & $8.89 E+04$ & 0.03 & 0.07 \\
\hline & & y3 & 1.29 & $2.14 \mathrm{E}+04$ & $2.76 \mathrm{E}+04$ & 0.16 & 0.04 \\
\hline & & b3 & 1.10 & $1.92 \mathrm{E}+04$ & $2.10 E+04$ & 0.18 & 0.14 \\
\hline \multirow[t]{4}{*}{ Slug } & HFNASK & b5 & 1.27 & $2.40 \mathrm{E}+05$ & $3.06 \mathrm{E}+05$ & 0.06 & 0.16 \\
\hline & & b10 & 1.05 & $9.96 \mathrm{E}+04$ & $1.04 \mathrm{E}+05$ & 0.13 & 0.07 \\
\hline & VSPPPPSDTSSK & b11 & 1.19 & 4.47E+04 & $5.34 \mathrm{E}+04$ & 0.07 & 0.05 \\
\hline & & y9 & 1.24 & $4.00 E+04$ & $4.96 \mathrm{E}+04$ & 0.07 & 0.06 \\
\hline
\end{tabular}

Summary of SRM-MS quantification results for E-Cadherin, Vimentin, Snail, and Slug. Mean peak area and coefficient of variation (CV) for each peptide fragment ion were derived from peak areas measured in three replicate assays of each of the sensitive and resistant cell line samples. Transitions with CV > 0.20 in either sample are not shown

expression data from those genes allowed reasonable separation between the drug sensitive and drug resistant ovarian tumours (Figure $5 \mathrm{~b}$ ).

\section{Discussion}

Ovarian cancer exhibits a high rate of platinum sensitivity in the first-line setting, but resistance frequently develops in recurrent disease [38]. As such, understanding the signaling networks that regulate chemoresistance is critical for successful treatment. This can be said of any cancer commonly treated with cisplatin such as small cell lung cancer, head and neck cancer, colorectal and hepatocelluar cancers.

While EMT has been widely studied for its role in early development and, more recently, cancer metastasis, it may also contribute to a cellular ability to evade the effects of platinum-based therapies. EMT results in the transformation of a differentiated epithelial cell to a mesenchymal cell with stem-like properties, and is characterized by loss of cell-to-cell adhesion, specifically through the dismantling of adherens, tight and gap junctions, as well as loss of cell polarity and increased motility [39]. In embryogenesis, EMT functions by promoting migration of mesenchymal cells, first, during gastrulation and neural crest cell migration, then later during tissue remodeling and organogenesis, ultimately contributing to the development of differentiated tissues with specific phenotypes [18]. In cancer progression, EMT appears to be at least partially responsible for the invasive nature of tumour cells and facilitates metastasis by converting a non-motile cancerous epithelial cell into a motile mesenchymal cell capable of disseminating from the tumour mass and entering the circulatory or lymphatic system [40]. It is widely believed that embryogenesis and cancer metastasis represent two facets of EMT, the former, a self-contained process that functions to generate diverse cell types and tissues, while the latter is affected by oncogenes and tumour suppressor genes resulting in invasion and metastatic spread through the circulatory system $[41,42]$.

It is likely that EMT in drug resistance may rely on many of the same transcription factors that function in embryogenesis and metastasis-related EMT, although details of their regulation are largely unknown. Studies from embryology and metastasis provide evidence to suggest that these cellular changes provide a survival advantage to cells under chemotoxic stress, for example, by down-regulating pro-apoptotic factors such as caspases and Dap1, or up-regulating anti-apoptotic factors Dad1 and Bcl2 [43,44]. Additionally, oxaliplatin-resistant 


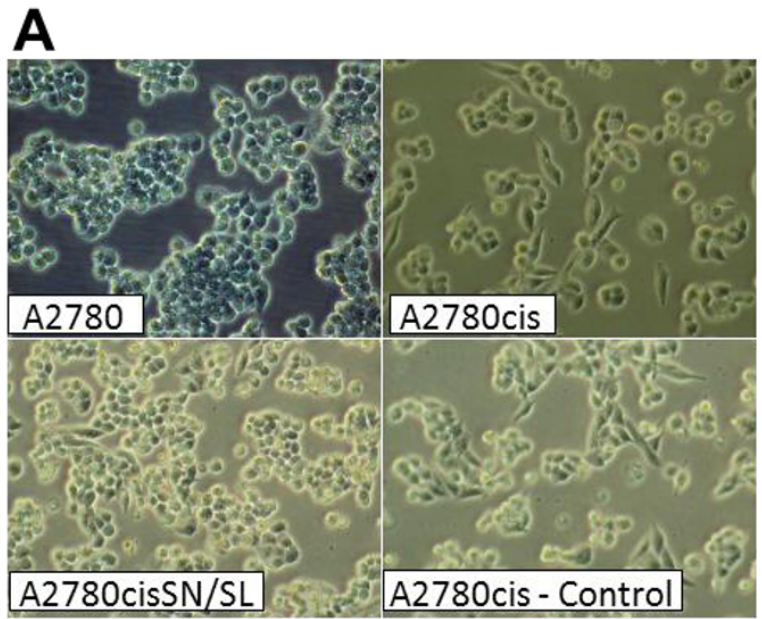

B

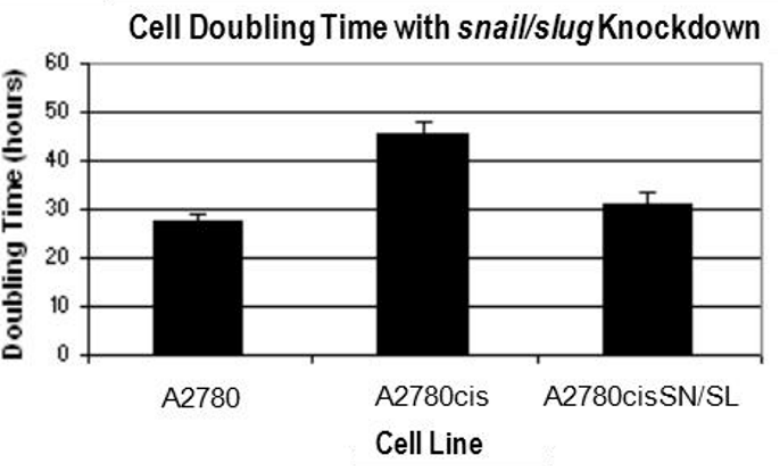

\section{Affects on Cell Migration and Irvasion with snail and slug Knockdown}

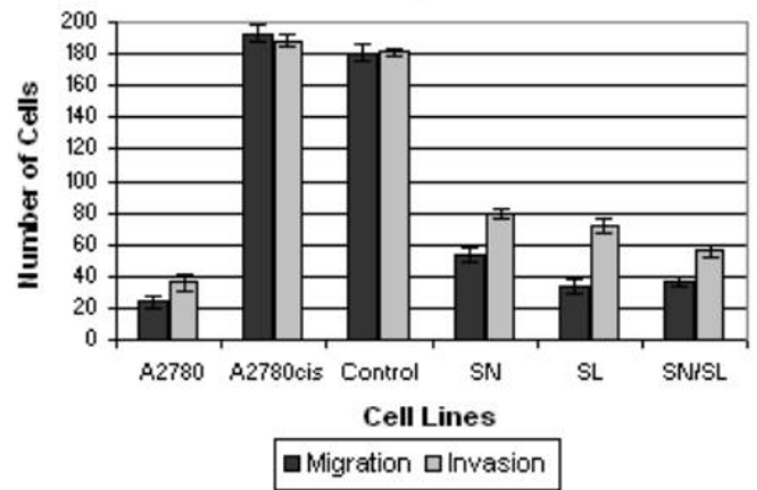

Figure 3 Knockdown of snail and slug reverses EMT phenotype. Snail and slug knockdown resulted in an epithelial morphology (a) and reduced the doubling time of the A2780cisSN/SL cells ( $p$-value $=0.017$ ) compared to the A2780cis cells $(\mathbf{b})$. Additionally, knockdown of snail and slug resulted in a reduction in migration from $194.0 \pm 7.0$ cells to $33.67 \pm 3.1$ cells migrating through the membrane $(p$-value $=0.002)$ as well as reducing invasion rate from $188.3 \pm 4.04$ cells to $56 \pm 4.58$ invading the matrix ( $p$-value $=0.004$ ), in each case, making the A2780cisSN/SL knockdown cells more similar to the A2780 cell line, having migration and invasion rates of $23.7 \pm 5.1$ and $36.3 \pm 5.03$, respectively (c). The control group, A2780cis cells transfected with a scrambled siRNA sequence, show no statistically significant changes in morphology, doubling time, migration or invasion.

colorectal cancer cells have been shown to display many of the hallmarks of EMT, including increased migration and invasion as well as a spindle-cell shape, loss of polarity and formation of pseudopodia [45]. Increased expression of zeb1 and decreased expression of E-cadherin have been associated with drug resistant pancreatic cell lines and reduction of zeb1 expression has been implicated in increased drug sensitivity [46]. In ovarian cancer cell lines, upregulation of snail and slug has been correlated with resistance to radiation and paclitaxel and shown to directly participate in p53-mediated pro-survival signaling [47]. Therefore the idea that the EMT genes play a significant role in cisplatin resistance in ovarian cancer is supported by previous evidence, and our own demonstration of a direct impact of these genes on platinum resistance.

Through the manipulation of key EMT signaling molecules, we have been able to show that we can resensitize drug resistant cells to the effects of cisplatin, approaching wild-type sensitivity after 72 hours in culture. Our findings suggest that genes known to regulate EMT directly contribute to cisplatin resistance in this ovarian cancer model. We do recognize that the A2780 cell line may not provide a faithful model of serous ovarian carcinoma, given that lineage fidelity for this line may not be maintained in long term culture. However, we conclude that the translation of our cell line derived results to a series of primary ovarian 

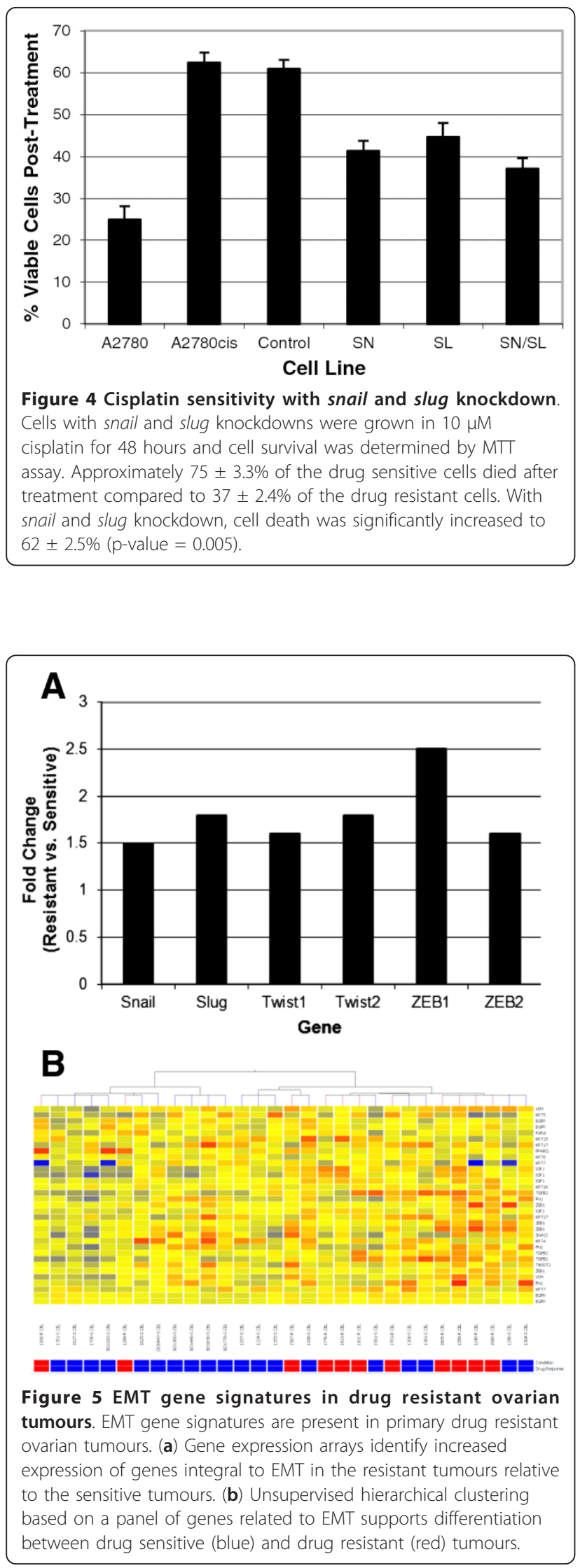

Table 2 List of genes used for unsupervised hierarchical clustering of primary tumours.

\begin{tabular}{cc}
\hline VIM & Vimentin \\
EGPR & Epidermal growth factor recetor \\
PPARG & Peroxisome proliferator-activated receptor gamma \\
IGF1 & Insulin-like growth factor 1 \\
TGFB2 & Transforming growth factor beta 2 \\
FN1 & Fibronectin \\
ZEB1 & Zinc finger E-box-binding homeobox 1 \\
SNAI2 & Slug (Zinc finger protein) \\
TWIST2 & Twist-related protein 2 \\
RXRA & Retinoid X receptor alpha \\
KRT5 & Keratin5 \\
KRT15 & Keratin15 \\
KRT17 & Keratin17 \\
KRT18 & Keratin18 \\
KRT7 & Keratin7 \\
KRT16 & Keratin16 \\
KRT4 & Keratin4 \\
\hline
\end{tabular}

Genes used to perform unsupervised hierarchical clustering on the primary ovarian tumours, chosen based on their documented involvement in EMT in recent literature

carcinomas provides evidence for the effectiveness of this model in this instance. We have demonstrated that a panel of EMT-related genes provides a reasonable model of classifying primary ovarian tumours according to their chemoresistance status. While we recognize that optimization of the biomarker panel would be required before suggesting this could provide a clinical benefit, this initial gene list identifies key differences in the underlying molecular circuitry of drug sensitive and resistant ovarian tumours. We have not determined whether this signature derives entirely from tumour cells, given that we did not enrich for tumour cells in our experiments; however, the fact that all of the primary tumours showed at least $70 \%$ tumour cells by histology would support the idea that the tumour likely contributes substantially to the signature we noted. To our knowledge, this is the first study in primary tumours demonstrating an EMT gene signature that can be used to differentiate between chemosensitive and chemoresistant human ovarian tumours and suggests that our overall findings may provide important clues about chemotherapy resistance in ovarian cancer.

\section{Conclusions}

In summary, we have demonstrated, through the use of an ovarian cancer cell line, A2780, and its cisplatinresistant daughter line, A2780cis, that the genes that regulate the epithelial to mesenchymal transition directly contribute to cisplatin-resistance in ovarian cancer. We have shown that when snail and slug, two key regulators 
of EMT, are knocked down in our cisplatin resistant cell line, the EMT phenotype is largely reversed and drug sensitivity is restored. Additionally, we demonstrate that this gene signature is present in drug resistant human ovarian tumours and that we can distinguish between drug sensitive and drug resistant ovarian tumours using the differential expression of a panel of EMT-related genes. Therefore, as it appears that EMT is connected to the drug resistant phenotype, this process and corresponding signaling network may be relevant biomarkers of drug resistance in ovarian cancer. Additionally, these molecules may represent targets for novel therapeutic strategies, used to overcome chemotherapy resistance in ovarian cancer, thereby modulating drug response in these patients and reducing the mortality rate associated with this disease.

\section{Additional material}

Additional file 1: Table S1 Clinical data for ovarian tumour samples. Available clinical data for each tissue sample including; patient's age at time of diagnosis (years), tumour stage, progression-free interval (PFl, months) and drug response classification.

\section{Abbreviations}

EMT: Epithelial to mesenchymal transition; LC/SRM-MS: Liquid chromatography/selected reaction monitoring mass spectrometry

\section{Acknowledgements}

The authors would like to thank Xiao Zhang from Queen's University Microarray Facility for his assistance with the gene expression arrays for the cell line data, and the Division of Gynecologic Oncology Ovarian Tissue Bank at the Ottawa Hospital for providing tumour samples and clinical follow up data. This study was conducted with the support of the Ontario Institute for Cancer Research through funding provided by the Government of Ontario. Additional funding was provided by the Queen's University Terry Fox Foundation Training Program in Transdisciplinary Cancer Research in partnership with CIHR.

\section{Author details}

'Department of Pathology and Molecular Medicine, Queen's University, 88 Stuart Street, Kingston, ON, K7L3N6, Canada. 'Division of Gynaecologic Oncology, The Ottawa Hospital, 501 Smyth Road, Ottawa, ON, K1H8L6, Canada. ${ }^{3} \mathrm{NCIC}$ Clinical Trials Group, Cancer Research Institute, 10 Stuart Street, Kingston, ON, K7L3N6, Canada. ${ }^{4}$ Ontario Cancer Biomarker Network, 101 College Street, Toronto, ON, M5G 1L7, Canada.

\section{Authors' contributions}

$\mathrm{AMH}$ carried out analysis of cell line microarray data, completed in vitro studies including cell migration, invasion and drug sensitivity assays, as well as gene knockdown experiments, and drafted the manuscript. MK provided microarray data for the primary tumours. MD, PN and JG carried out bioinformatic analysis of microarray data. MD and PN also designed peptide sequences for SRM-MS. KE, JC and JL carried out targeted protein quantification via SRM-MS and subsequent analysis. JW carried out classification of primary tumours as drug sensitive or resistant using clinical data. TC examined the primary tumours and calculated the percent tumour cells. SD provided guidance on biological interpretations. JS and HF conceived of the study, and participated in its design. AMH, SD, JS, PCP and $\mathrm{HF}$ all made significant intellectual contributions to this study. All authors contributed to the editing of this manuscript. All authors read and approved the final manuscript.

\section{Competing interests}

The authors declare that they have no competing interests.

Received: 13 December 2011 Accepted: 19 March 2012

Published: 19 March 2012

\section{References}

1. Khalil I, Brewer MA, Neyarapally T, Runowicz CD: The potential of biologic network models in understanding the etiopathogenesis of ovarian cancer. Gynecol Oncol 2010, 116(2):282-285.

2. Köbel M, Kalloger SE, Boyd N, McKinney S, Mehl E, Palmer C, Leung S, Bowen NJ, lonescu DN, Rajput A, Prentice LM, Miller D, Santos J, Swenerton K, Gilks CB, Huntsman D: Ovarian carcinoma subtypes are different diseases: Implications for biomarker studies. PLOS Med 2008, 5(12):1749-1760

3. Canadian Cancer Society: Canadian Cancer Statistics. Statistics Canadal Public Health Agency of Canada 2011 [http://www.cancer.ca].

4. Holschneider C, Berek J: Ovarian cancer: epidemiology, biology, and prognostic factors. Semin Surg Oncol 2000, 19:3-10.

5. Moore R, MacLaughlin S: Current clinical use of biomarkers for epithelial ovarian cancer. Curr Opin Oncol 2010, 22(5):492-497.

6. Kulasingam $V$, Pavlou MP, Diamandis EP: Integrating high-throughput technologies in the quest for effective biomarkers for ovarian cancer. Nat Rev 2010, 10(5):371-378.

7. Visintin I, Feng Z, Longton G, Ward DC, Alvero AB, Lai Y, Tenthorey J, Leiser A, Flores-Saaib R, Yu H, Azori M, Rutherford T, Schwartz PE, Mor G: Diagnostic markers for early detection of ovarian cancer. Clin Cancer Res 2008, 14(4):1065-1072.

8. Dressman HK, Berchuck A, Chan G, Zhai J, Bild A, Sayer R, Cragun J, Clarke J, Whitaker RS, Li L, Gray J, Marks J, Ginsburg GS, Potti A, West M, Nevins JR, Lancaster JM: An integrated genomic-based approach to individualized treatment of patients with advanced stage ovarian cancer. J Clin Oncol 2007, 25(5):517-525.

9. Yen MS, Juang CM, Lai CR, Chao GC, Ng HT, Yuan CC: Intraperitoneal cisplatin-based chemotherapy vs. intravenous cisplatin-based chemotherapy for stage III optimally cytoreduced epithelial ovarian cancer. Int J Gynaecol Obstet 2001, 72(1):55-60.

10. Hogberg T: Chemotherapy: current drugs still have potential in advanced ovarian cancer. Nat Rev Clin Oncol 2010, 7(4):191-193.

11. Marsh S: Pharmacogenomics of Taxane/Platinum therapy in ovarian cancer. Int J Gynecol Cancer 2009, 2:30-34.

12. Galluzzi L, Senovilla L, Vitale I, Michels J, Martins I, Kepp O, Castedo M, Kroemer G: Molecular mechanisms of cisplatin resistance. Oncogene 2011, doi:10.1038/onc.2011.384.

13. Konstantinopolous PA, Spentzos D, Cannistra S: Gene-expression profiling in epithelial ovarian cancer. Nat Clin Pract Oncol 2008, 5:577-587.

14. Li J, Wood WH, Becker KG, Weeraratna AT, Morin PJ: Gene expression response to cisplatin treatment in drug-sensitive and drug-resistant ovarian cancer cells. Oncogene 2007, 26:2860-2872.

15. Cheng TC, Manorek G, Samimi G, Lin X, Berry CC, Howell SB: Identification of genes whose expression is associated with cisplatin resistance in human ovarian carcinoma cells. Cancer Chemother Pharmacol 2006, 58:384-395.

16. Ahmad S: Platinum-DNA interactions and subsequent cellular processes controlling sensitivity to anticancer platinum complexes. Chem Biodivers 2010, 7(3):543-566.

17. Burger H, Loos WJ, Eechoute K, Verweij J, Mathijssen RH, Wiemer EA: Drug transporters of platinum-based anticancer agents and their clinical significance. Drug Resist Update 2011, 14(1):22-34.

18. Hay E: The mesenchymal cell, its role in the embryo, and the remarkable signaling mechanisms that create it. Dev Dyn 2005, 233(3):706-720.

19. Kalluri $R$, Weinberg $R$ : The basics of Epithelial-Mesechymal transition. J Clin Invest 2009, 119(6):1420-1428.

20. Micalizzi D, Farabough FM, Ford H: Epithelial-Mesenchymal transition in cancer: parallels between normal development and tumour progression. J Mam Gland Biol Neoplasia 2010, 15:117-134.

21. Acloque H, Adams MS, Fishwick K, Bronner-Fraser M, Nieto MA: Epithelialmesenchymal transitions: the importance of changing cell state in development and disease. J Clin Invest 2009, 119(6):1438-1449.

22. Soo K, O'Rourke MP, Khoo PL, Steiner KA, Wong N, Behringer RR, Tam PP: Twis function is required for the morphogenesis of the Cephalic neural 
tube and the differentiation of the Cranial neural crest cells in the mouse embryo. Dev Biol 2002, 247(2):251-270.

23. Ekblom P: Genetics of kidney development. Curr Opin Nephrol Hypertens 1996, 5(3):282-287.

24. Geiger TR, Peeper DS: Metastasis mechanisms. Biochim Biophys Acta 2009 1796:293-308.

25. Zlobec I, Lugli A: Epithelial mesenchymal transition and tumor budding in aggressive colorectal cancer: tumor budding as oncotarget. Oncotarget 2010, 1(7):651-661.

26. Iwatsuki M, Mimori K, Yokobori T, Ishi H, Beppu T, Nakamori S, Baba H, Mori M: Epithelial-mesenchymal transition in cancer development and its clinical significance. Canc Sci 2009, 101(2):293-299.

27. Sabe H: Cancer early dissemination: cancerous epithelial-mesenchymal transdifferentiation and transforming growth factor $\beta$ signalling. J Biochem 2011, 149(6):633-639.

28. Zhang K, Chen D, Jiao X, Zhang S, Liu X, Cao J, Wu L, Wang D: Slug enhances invasion ability of pancreatic cancer cells through upregulation of matri metalloproteinase-9 and actin cytoskeleton remodeling. Lab Invest 2011, 91(3):426-438.

29. Zhao XL, Sun T, Che N, Sun D, Zhao N, Dong XY, Gu Q, Yao Z, Sun BC: Promotion of hepatocellular carcinoma metastasis through matrix metalloproteinase activation by epithelial-mesenchymal transition regulator Twist1. J Cell Mol Med 2011, 15(3):691-700.

30. Işeri OD, Kars MD, Arpaci F, Atalay C, Pak I, Gündüz U: Drug resistant MCF7 cells exhibit epithelial- mesenchymal transition gene expression pattern. Biomed and Pharmacotherapy 2011, 65(1):40-45.

31. Helleman J, Smid M, Jansen MP, van der Berg ME, Berns EM: Pathway analysis of gene lists associated with platinum-based chemotherapy resistance in ovarian cancer: the big picture. Gynecol Oncol 2010, 117(2):170-176.

32. Chang TH, Tsai MF, Su KY, Wu SG, Huang CP, Yu SL, Yu YL, Lan CC, Yang $C H$, Lin SB, Wu CP, Shih JY, Yang PC: Slug confers resistance to the epidermal growth factor receptor tyrosine kinase inhibitor. Am J Respir Crit Care Med 2010, 183(8):1071-1079.

33. McConkey DJ, Choi W, Marquis L, Martin F, Williams MB, Shah J, Svatek R, Das A, Adam L, Kamat A, Siefker-Radtke A, Dinney C: Role of epithelial-tomesenchymal transition (EMT) in drug sensitivity and metastasis in bladder cancer. Canc Met Rev 2009, 28(3-4):335-344.

34. Vega S, Morales AV, Ocaña OH, Valdés F, Fabregat I, Nieto MA: Snail blocks the cell cycle and confers resistance to cell death. Genes Dev 2004, 18(10):1131-1143.

35. Saxena M, Stephens MA, Pathak H, Rangarajen A: Transcription factors that mediate epithelial-mesenchymal transition lead to multidrug resistance by upregulating ABC transporters. Cell Death and Disease 2011, 2(6):e179.

36. Wu K, Bonavida B: The activated NF-kappaB-Snail-RKIP circuitry in cancer regulates both the metastatic cascade and resistance to apoptosis by cytotoxic drugs. Crit Rev Immunol 2009, 29(3):241-254.

37. Schmittgen $T$, Livak K: Analyzing real-time PCR data by the comparative $C_{T}$ method. Nat Protoc 2008, 3(6):1101-1108.

38. Solar P, Sytkowski AJ: Differentially expressed genes associated with cisplatin resistance in human ovarian adenocarcinoma cell line A2780. Cancer Lett 2011, 309(1):11-18.

39. Moustakas A, Heldin CH: Signaling networks guiding epithelialmesenchymal transitions during embryogenesis and cancer progression. Cancer Sci 2007, 98(10):1512-1520.

40. Yang J, Weinberg R: Epithelial-Mesenchymal transition: at the crossroads of development and tumor metastasis. Dev Cell 2008, 14(6):818-829.

41. Zeisberg M, Neilson E: Biomarkers for epithelial-mesenchymal transitions. J Clin Invest 2009, 119(6):1429-1437.

42. Kalluri R: EMT: When epithelial cells decide to become mesenchymal-like cells. J Clin Invest 2009, 119:1417-1419.

43. LaGamba D, Nawshad A, Hay E: Microarray analysis of gene expression during epithelial-mesenchymal transformation. Dev Dynamics 2005, 234:132-142.

44. Sun $T$, Sun $B C$, Zhao $X L$, Zhao $N$, Dong $X Y$, Che N, Yao Z, Ma YM, Gu $Q$ Zong WK, Liu ZY: Promotion of tumor cell metastasis and vasculogenic mimicry by way of transcription coactivation by $\mathrm{BCl}-2$ and Twist1: A study of hepatocellular carcinoma. Hepatology 2011, doi:10.1002/ hep.24543.

45. Yang D, Wang AH: Structural studies of interactions between anticancer platinum drugs and DNA. Prog Biophys Mol Biol 1996, 66(1):81-111.
46. Arumugam $T$, Ramachandran V, Fournier $K F$, Wang $H$, Marquis $L$, Abbruzzese JL, Gallick GE, Logsdon CD, McConkey DJ, Choi W: Epithelial to mesencymal transition contributes to drug resistance in pancreatic cancer. Canc Res 2009, 69(14):5820-5828.

47. Kurrey NK, Jalgaonkar SP, Joglekar AV, Ghanate AD, Chaskar PD, Doiphode RY, Bapat SA: Snail and slug mediate radioresistance and chemoresistance by antagonizing p53-mediated apoptosis and acquiring a stem-like phenotype in ovarian cancer cells. Stem Cells 2009, 27(9):2059-2068.

\section{Pre-publication history}

The pre-publication history for this paper can be accessed here: http://www.biomedcentral.com/1471-2407/12/91/prepub

doi:10.1186/1471-2407-12-91

Cite this article as: Haslehurst et al.: EMT transcription factors snail and slug directly contribute to cisplatin resistance in ovarian cancer. $B M C$ Cancer 2012 12:91.

\section{Submit your next manuscript to BioMed Central and take full advantage of:}

- Convenient online submission

- Thorough peer review

- No space constraints or color figure charges

- Immediate publication on acceptance

- Inclusion in PubMed, CAS, Scopus and Google Scholar

- Research which is freely available for redistribution 